\title{
Distribuição sazonal e longevidade das larvas infestantes de nematódeos gastrintestinais de bovinos em pastagens na Baixada Fluminense, Rio de Janeiro
}

\author{
Seasonal distribution and longevity of infective larvae of cattle \\ gastrointestinal nematodes in pastures of the "Baixada Fluminense", \\ region of the State of Rio de Janeiro, Brazil
}

\author{
Manoel Pimentel Neto, ${ }^{\star} \quad$ Maria Cristina Ribeiro, ${ }^{\star *}$ Adivaldo Henrique da Fonseca***
}

\begin{abstract}
Resumo
Estudou-se a distribuição estacional da eliminação de ovos por grama de fezes e sobrevivência das larvas infestantes no bolo fecal e pastagens de Haemonchus placei, Trichostrongylus axei, Cooperia punctata e Oesophagostomum radiatum. O experimento foi conduzido em piquetes na Baixada Fluminense, estado do Rio de Janeiro, e as amostras dos bolos fecais de bezerros mestiços zebu $\mathrm{x}$ holandês e da pastagem foram examinados a cada 14 dias para contagem das larvas infestantes. As maiores contagens de ovos por grama de fezes ocorreu no final do inverno e primavera, coincidindo com a temperatura amena e elevada umidade relativa. A sobrevivência de larvas no bolo fecal e na pastagem foi alta na primavera, esporádica ou baixa nas estações de verão e outono, exceto para larvas do gênero Cooperia, que demostraram capacidade de sobrevivência nas elevadas temperaturas e condições ecológicas desfavoráveis. Os resultados indicam que as larvas dos helmintos são susceptíveis à temperatura elevada observada no verão e início da estação de outono, sugerindo ser esta a melhor época para estabelecimento de manejo estratégico para controle das helmintoses na região estudada.
\end{abstract}

Palavras-chave: Epidemiologia de helmintos; ruminantes; bovinos; nematódeos gastrintestinais.

\begin{abstract}
The seasonal distribution of the elimination of eggs per gram of faeces and the survival of larvae infecting the dung pads and pastures was studied for Haemonchus placei, Trichostrongylus axei, Cooperia punctata and Oesophagostomum radiatum. The experiment was carried out in fields of the "Baixada Fluminense" Region of the State of Rio de Janeiro, Brazil. Dung pad samples of the cross breed Zebu x Holstein-Friesian calves and pasture samples were examined every 14 days for counts of infestive larvae. The highest counts of eggs per gram of faeces occurred at the end of winter and in spring, coinciding with warmer temperatures and higher levels of relative humidity. The survival of larvae in the dung pads and in the pastures was high in the spring, sporadic or low in the summer and autumn, except for larvae of the genus Cooperia that showed an ability to survive in high temperatures and unfavourable ecological conditions. The results indicate that the helminth larvae are susceptible to the higher temperatures observed in the summer and early autumn, suggesting this to be the best period for the establishment of strategic management for the control of these helminths in the region studied.
\end{abstract}

Keywords: Epidemiology of helminths; ruminants; cattle; gastrointestinal nematodes.

\section{Introdução}

No desenvolvimento e sobrevivência das larvas de vida ivre, o microclima exerce papel importante, pois, segundo Levine, Todd (1975), microclimas semelhantes podem ocorrer em condições climáticas diferentes. Segundo Rosemberg (1974), microclima é o espaço onde vivem as plantas e os animais. As diferenças no ecossistema determinam as variações no desenvolvimento das larvas dos nematódeos no meio ambiente e a prevalência das espécies envolvidas. Durante o ciclo evolutivo, os estágios pré-infestantes de nematódeos gastrintestinais sofrem influência da temperatura, precipitação pluviométrica, umidade, luz solar, evaporação, oxigênio, tipo de solo e pastagem (Reinecke, 1970).

Durie (1961), estudando o comportamento das larvas infestantes de bovinos no pasto e no bolo fecal, verificou que as condições ambientais dentro do bolo fecal foram favoráveis ao desenvolvimento das larvas em todas as estações do ano, exceto no meio do verão e inverno. Os bolos fecais depositados no

\footnotetext{
*Médico Veterinário, Doutor, Bolsista da Fundação de Amparo à Pesquisa do estado do Rio de Janeiro - FAPERJ.

**Médica Veterinária autônoma - RJ (Trabalho em parte extraído da Tese de Mestrado em Patologia Veterinária - UFRRJ).

***Professor Titular do Departamento de Epidemiologia e Saúde Pública da Universidade Federal Rural do Rio de Janeiro. Cx. Postal 74548 , CEP 23851-970 Seropédica, RJ - e-mail [adivaldo@ ufrrj.br].
} 
verão permaneceram como fonte de larvas por cinco meses. Este período se estendeu por sete a oito meses quando a deposição da massa fecal ocorreu no inverno. Dinnik e Dinnik (1961) contaminaram artificialmente pastagens com Haemonchus contortus e observaram que, no período quente e seco, a sobrevivência máxima das larvas foi de cinco semanas, sendo o mais curto observado.

No Brasil, Catto (1987), trabalhando na região do pantanal mato-grossense, confirmou que os bolos fecais depositados no início da estação seca, a pastagem ao seu redor permaneceram positivos para larvas infestantes por seis meses, enquanto os depositados na estação quente e chuvosa foram positivos por apenas dois meses.

Gonçalves e Vieira (1963), no Rio Grande do Sul, observaram que, durante o verão, as larvas desapareceram das pastagens ao fim de dois meses, quando a temperatura média foi elevada $\left( \pm 25^{\circ} \mathrm{C}\right)$ e a umidade relativa em torno de $60 \%$. Guimarães, em 1972, encontrou um número pequeno de larvas nas pastagens durante o período seco em Zona do Cerrado de Minas Gerais.

Braga (1986), trabalhando na Baixada Fluminense com nematódeos gastrintestinais de bovinos, recuperou larvas de Cooperia spp, Haemonchus spp, Trichonstrongylus spp e Oesophagostomum spp. O autor concluiu que houve condições favoráveis para a sobrevivência de larvas infestantes durante todo o experimento e que a precipitação pluviométrica foi fator importante na persistência das larvas infestantes nas massas fecais e em sua dinâmica sobre a pastagem.

\section{Material e métodos}

Os estudos foram conduzidos em pastagens e nos laboratórios de Parasitologia da Embrapa, atual Setor de Doenças Parasitárias da UFRRJ, situado a $22^{\circ} 45^{\prime}$ de longitude oeste, altitude de 33 metros. Todos os animais utilizados no experimento eram procedentes da estação experimental da Pesagro-Rio, Seropédica, RJ, e a pesquisa foi realizada entre agosto de 1981 e janeiro de 1983.

O clima da região, segundo a classificação de Köppen, é do tipo Aw, com inverno seco, verão chuvoso e quente. A temperatura média das médias do mês mais quente (janeiro) é superior a $33^{\circ} \mathrm{C}$ e a precipitação média no verão é superior a $739 \mathrm{~mm}$ e, no inverno, $128 \mathrm{~mm}$. O solo é do tipo franco argiloso arenoso e o pasto constituído por capim Digitaria decumbens.

O terreno era levemente acidentado e as fezes foram defecadas espontaneamente pelos próprios animais. Um termohidrógrafo' ${ }^{1}$ foi instalado a $10 \mathrm{~cm}$ do solo e. no próprio piquete, para medir a temperatura das máximas e mínimas e a umidade relativa do ar no local do experimento. O posto oficial de observação meteorológica ficava situado a $1 \mathrm{~km}$ do local do experimento.

Para estabelecimento da contagem de ovos por grama de fezes (o.p.g.) utilizaram-se fezes coletadas diretamente da ampola retal, utilizando-se a Técnica de Gordon e Whitlock (1939). Em seguida, foi feita a coprocultura segundo Robert O'Sullivan (1950) para a obtenção das larvas infestantes, e a

\footnotetext{
1 Marca Schreibstreifeu.
}

chave de Keith (1953) para identificação específica.

Para manter a infestação da pastagem com larvas, quatro bezerros, com idade variando entre quatro e nove meses, mestiços de zebu $x$ holandês, eram mantidos em um piquete contíguo e destinado a experimento com animais traçadores. Um dos quatro bezerros, que apresentava maior o.p.g., era colocado em um piquete com $450 \mathrm{~m}^{2}$ a cada 14 dias, permanecendo durante uma noite. Após a retirada do bezerro, marcaram-se duas massas fecais frescas, encontradas nas pastagens, identificando-as como "massa fecal teste" (MFT) e "massa fecal controle" (MFC), em torno das quais foi colocado um suporte de madeira, com a finalidade de protegê-las do pisoteio. Uma semana após, coletava-se amostra da MFT para obtenção de larvas, utilizando-se a Técnica de Baermann modificada por Ueno (1968), sendo esta operação repetida a cada 14 dias.

Para obtenção das larvas, o pasto correspondente à MFT era cortado rente ao solo, numa área de $5 \mathrm{~cm}$ de largura por $30 \mathrm{~cm}$ de comprimento, segundo metodologia preconizada por Rose (1970). Utilizou-se, então, a Técnica de Donald (1967) para a recuperação de larvas da pastagem. A MFC era trabalhada utilizando-se esta mesma metodologia, quando a MFT correspondente se apresentava por duas vezes negativa.

\section{Resultados e discussão}

As larvas infestantes recuperadas foram de Haemonchus placei (Place, 1893) Ransom, 1911, Trichostrongylus axei (Cobbold, 1879) Railliet, Henry, 1909 Cooperia punctata (von Linstow, 1907) Ransom, 1907 e Oesophagostomum radiatum (Rudolphi, 1803) Railliet, 1898. Larvas de Strongyloides papilosus também foram encontradas, mas por não apresentarem freqüência nos achados, não foram incluídas neste estudo.

Gordon (1948), baseando-se nos fatores micrometeorológicos, foi o primeiro a introduzir o uso dos dados bioclimatográficos para avaliar as condições climáticas favoráveis ao desenvolvimento dos nematódeos. Levine e Todd (1975) avaliaram vários fatores, entre eles, a precipitação, orvalho, umidade relativa, temperatura-padrão, temperatura em 2 e $5 \mathrm{~cm}$ acima da superfície do solo, e afirmaram que os fatores micrometeorológicos determinam se as larvas poderão sobreviver no pasto e que a média das temperaturas máximas é um fator importante, podendo determinar um efeito letal sobre as mesmas.

Ocorreram chuvas durante todos os meses do experimento, porém, nos meses de outubro a abril (primavera, verão e início de outono), quando se constataram os maiores índices pluviométricos (Figura 1). O maior índice observado foi de $250 \mathrm{~mm}$ no mês de dezembro e o menor, $20,6 \mathrm{~mm}$ para o mês de maio. Os dados referentes à umidade relativa do microclima em relação aos do padrão foram bem diferenciados, principalmente nos meses de inverno e primavera e foram acima de $65 \%$ para todos os meses do ano. A média das máximas para o verão ao nível do solo foi de $37,4^{\circ} \mathrm{C}$ e, na estação meteorológica, foi de $33^{\circ} \mathrm{C}$, tendo sido observado no mês de janeiro. A média mínima mais fria foi observada no mês de julho, $17,7^{\circ} \mathrm{C}$ ao nível do solo, e $17,1^{\circ} \mathrm{C}$ na estação meteorológica (Figura 1). 


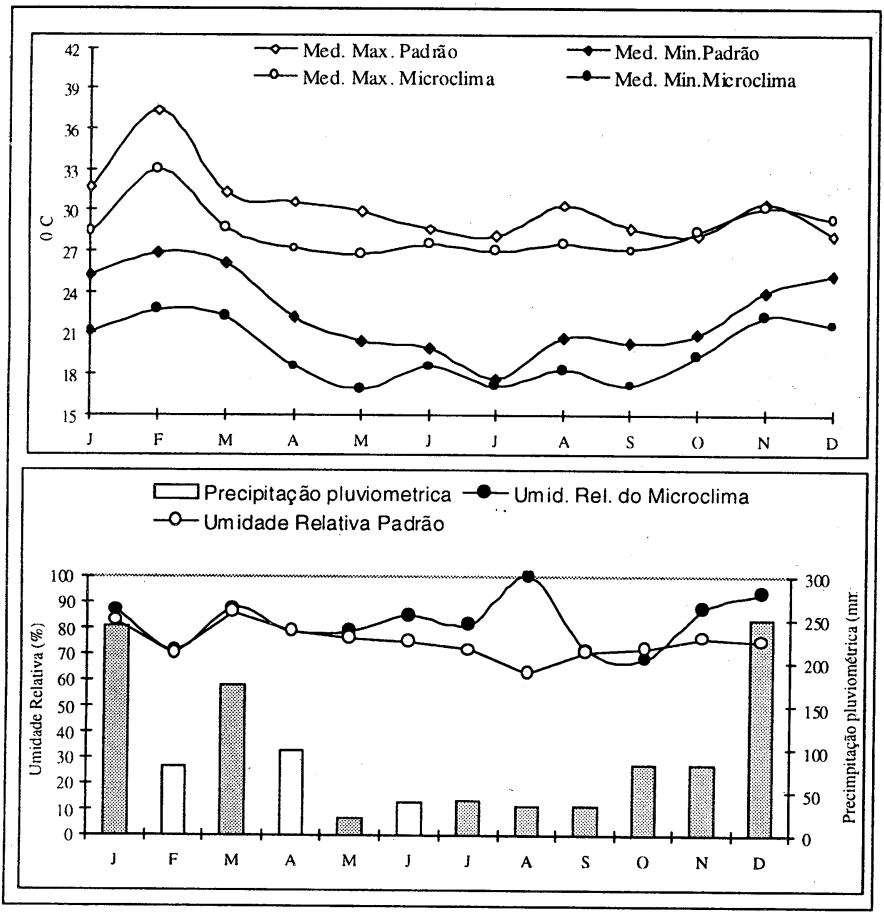

Figura 1: Dados climáticos das médias das Temperaturas Máximas e Mínimas, Umidade Relativa (Padrão e Microclima) e Precipitação Pluviométrica, obtidos na estação experimental da Pesagro-Rio, Seropédica, RJ.

A contagem de ovos por grama de fezes foi baixa para todos os helmintos no final do verão, outono e início do inverno, com pique no final do inverno, primavera e início do verão (Figura $2 a, b, c, d$ ).

Poucas ou nenhuma larva de $H$. placei foram recuperadas do bolo fecal entre janeiro e agosto, tendo sido observado pique entre setembro e novembro (Figura 2 e). Estes resultados foram semelhantes aos encontrados por Skinner et al. (1980), Melo (1977) e Braga (1986), todos trabalhando em regiões de verão chuvoso. Skinner et al. (1980) estudaram a migração lateral de $H$. contortus nas pastagens e concluíram que quando a temperatura diminui, a migração e sobrevivência das larvas aumentam. Dinaburg (1944) contaminou artificialmente pastagens com larvas de $H$. contortus e concluiu que, no verão e inverno, as condições foram desfavoráveis para a sobrevivência das larvas.

Constatou-se que larvas de $T$. axei foram encontradas no bolo fecal durante os 18 meses que durou o experimento, sendo o único nematódeo que apresentou pique de larvas dentro do bolo fecal no verão (Figura $2 \mathrm{f}$ ). $\mathrm{O}$ pique de larvas nas pastagens foi constatado período da primavera, embora o número de larva tenha sido inexpressivo em relação aos demais nematódeos. Resultados semelhantes foram relatados por Catto (1982).

Houve condições favoráveis para que as larvas de C. punctata sobrevivessem dentro do bolo fecal em todas as estações do ano, com pique no verão e primavera (Figura $2 \mathrm{~g}$ ). Os dados demonstram que, quando aumentou o número de larvas nas pastagens, diminuíram no bolo fecal, demonstrando, assim, a sua migração para o pasto. As larvas de C. punctata foram recuperadas das pastagens em maior número, a partir do outono até a primavera (Figura $2 \mathrm{k}$ ). Estes resultados são semelhantes aos encontrados por Reinecke (1960b), na África do Sul, o qual concluiu que as larvas de Cooperia spp foram mais adaptadas às condições de dissecação e altas temperaturas e por Braga (1986), que afirmou ser Cooperia o gênero com maior capacidade de adaptação para sobrevivência.

As larvas de 0 . radiatum mantiveram níveis baixos no bolo fecal nas estações de verão e início do outono, com pique no inverno e primavera (Figura $2 \mathrm{~h}$ ). A recuperação de larvas na pastagem foi baixa ou nula no verão, outono e inverno e em grande número na primavera (Figura $2 \mathrm{l}$ ).

Mello, em 1977, trabalhando na Zona do Cerrado de Mato Grosso, recuperou um número de larvas relativamente baixo durante a estação seca. Guimarães (1972) utilizou bovinos para a contaminação das pastagens, recuperando maior número de larvas infestantes no início da estação chuvosa (novembro). Nos meses de dezembro e janeiro, apesar da temperatura e precipitação pluviométrica estarem acima das exigências mínimas para o desenvolvimento dos estágios pré-infestantes, não houve recuperação de larvas. Gonçalves e Vieira (1963) concluíram que,

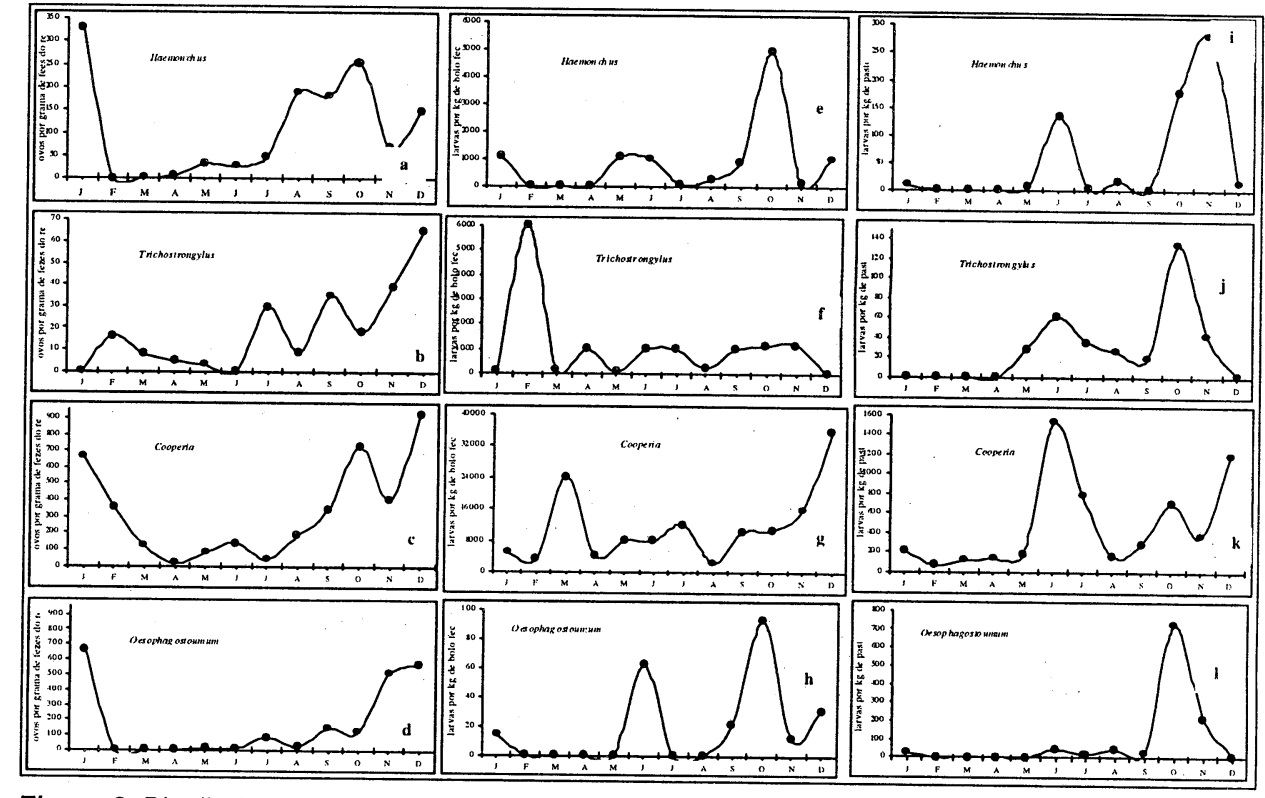

Figura 2: Distribuição sazonal de ovos (a, b, c, d), larvas infestantes no bolo fecal (e, f, g, h) e larvas infestantes nas pastagens (i, j, k, l), de Haemonchus placei, Trichostrongylus axei, Cooperia punctata e Oesophagostomum radiatum, na Baixada Fluminense, Rio de Janeiro.

no verão, a época mais quente e seca do ano no Rio Grande do Sul, as condições não foram favoráveis para o crescimento das 
larvas de ovinos nas pastagens. Amarante et al. (1996) relataram que as maiores infestações da pastagem por larvas infectantes de Haemonchus spp, Trichostrongylus spp. e Cooperia spp. ocorreram de maio a outubro. As maiores quantidades de larvas de Oesophagostomum spp. foram registradas de setembro a novembro e a contaminação da pastagem foi relativamente elevada em junho, julho e agosto, apesar das baixas precipitações ocorridas. Resultados equivalentes foram obtidos no presente trabalho.

Houve destruição dos bolos fecais por coleópteros coprófagos e provavelmente por formigas, com maior ocorrência no verão e final de outono, quando algumas massas fecais foram totalmente destruídas. Os bolos fecais que sofriam ação destes organismos apresentaram-se parcialmente destruídos, com buracos de aproximadamente $3 \mathrm{~mm}$ de diâmetro. A ação dos coleópteros e outros organismos como agentes que interferem no desenvolvimento dos ovos e larvas foi citada por Goldberg (1968). Bryan (1976) reportou que 10 a 30 pares de coleópteros coprófagos da espécie Onthophagus gazella foram capazes de reduzir em até $74 \%$ a população de larvas de nematódeos gastrintestinal de bovinos no pasto em condições de clima úmido. Reinecke (1960) descreveu que coleópteros e outros artrópodes foram muito ativos no bolo fecal e que a ação destes organismos provoca a destruição parcial e favorece a eclosão dos ovos ao aumentar a aeração das fezes. Por outro lado, segundo o autor, o rápido ressecamento das partes internas da massa fecal torna o ambiente de difícil sobrevivência para as larvas infestantes.

As elevadas temperaturas observadas durante o verão, ao nível do microclima (Figura 1), constituiu-se em fator limitante para a sobrevivência e longevidade das larvas no bolo fecal e nenhuma larva sobreviveu por mais de dois meses. Larvas de $H$. placei sobreviveram por até 140 dias nas estações de outono e inverno e os demais sobreviveram entre 60 e 90 dias. A longevidade foi superior a 80 dias para todas as espécies no bolo fecal, durante a primavera (Figura 3 a).

A sobrevivência de larvas no pasto foi esporádica ou nenhuma no verão, exceto para larvas do gênero Cooperia, que demostraram capacidade de sobrevivência por uma semana nas elevadas temperaturas e condições ecológicas desfavoráveis (Figura $3 \mathrm{~b}$ ).

Larvas de todos os nematódeos sobreviveram por mais de 70 dias nas pastagens nos períodos de outono e inverno (Figura 3b). A maior longevidade das larvas nos períodos de outono e inverno se deveu provavelmente à temperatura amena e elevada umidade relativa observada no período. Na primavera, $O$. radiatum foi a larva com maior sobrevivência no pasto, tendo sobrevivido por até 98 dias (Figura 3 b).

É provável que, ocorrendo precipitação pluviométrica regularmente distribuída durante o verão, diminuindo a média da temperatura máxima, possa ocorrer condições favoráveis para estabelecimento de parasitose clínica. Os resultados indicam que as larvas dos helmintos estudados são susceptíveis a temperaturas elevadas observadas no verão e início da estação de outono, sugerindo ser esta a melhor época para estabelecimento de manejo estratégico para controle das helmintoses, na região estudada.

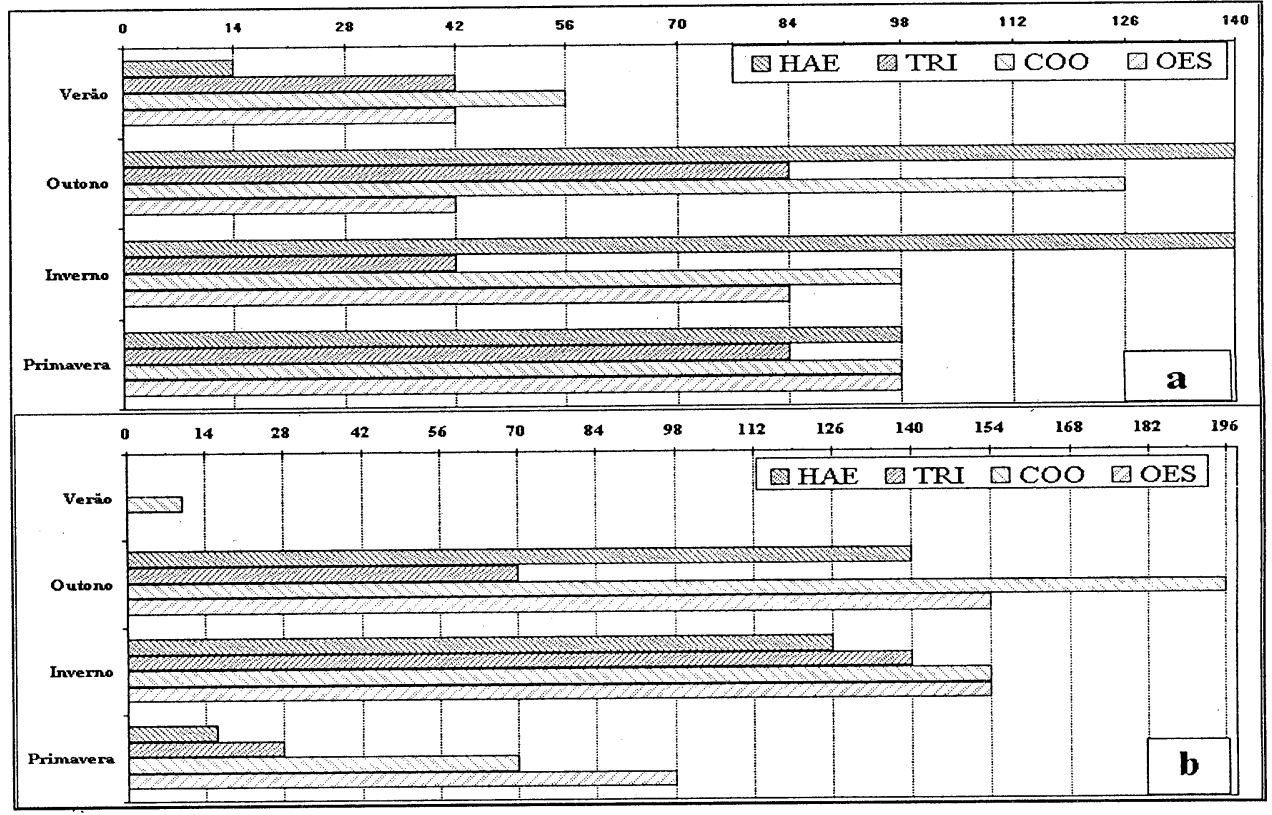

Figura 3: Longevidade, em dias, das larvas infestantes de Haemonchus placei, Trichostrongylus axei, Cooperia punctata e Oesophagostomum radiatum. a - no bolo fecal, e b - na pastagem, na Baixada Fluminense, Rio de Janeiro.

\section{Conclusões}

Final de outono, inverno e primavera foram as épocas mais favoráveis para a sobrevivência das larvas de H. placei, T. axei, $C$. punctata $e$ O. radiatum dentro do bolo fecal, bem como nas pastagens.

Larvas de $C$. punctata foram mais prevalentes e que melhor se adaptaram às condições climáticas da região estudada.

Coleópteros coprófagos e provavelmente formigas contribuiram para a diminuição da população dos nematódeos nas pastagens, pois destruíram os bolos fecais.

As temperaturas elevadas observadas no verão e início do outono inviabilizam a sobrevivência das larvas infestantes. 


\section{Referências bibliográficas}

AMARANTE, A.F.T., PADOVANI, C.R., BABOSA, M.A. Contaminação da pastagem por larvas infectantes de nematódeos gastrintestinais parasitas de bovinos e ovinos em Botucatu-SP. Rev Bras Parasitol Vet., v. 5, p. 65-73, 1996.

BRAGA, R.M. Sobrevivência de larvas infestantes de nematóides gastrintestinais de bovinos, sob condições naturais. Rev Bras Med Vet., v. 8, p. 186-188, 1986.

BRYAN, R.P. The effect of the dung beatle, Onthophagus gazellaon the ecology of the infective larvae of gastrointestinal nematodes of cattle. Aust J Agric Res., v. 27, p. 567-574, 1976.

CATTO, J.B. Desenvolvimento e sobrevivência de larvas infectantes de nematóides gastrintestinais de bovinos durante a estação seca, no pantanal mato-grossense. Pesq́. Agrop. Bras., v. 17, p. 923927, 1982.

. Longevidade de larvas infectantes de nematódeos gastrintestinais de bovinos no pantanal mato-grossense. Pesq Agrop. Bras., v. 22, p. 847-854, 1987.

DINABURG, A.G. Development and survival under outdoor conditions of eggs and larvae of the common ruminant stomach woem, Haemonchus contortus. J Agri Res., v. 69, p. 421-433, 1944.

DINNIK, J.A., DINNIK, N.N. Observation on the longevity of Haemonchus contortus larvae on pasture herbage in the kenya highlands. Bull Epid Dis Afr., v. 9, p. 193-208, 1961.

DONALD, A.B. A technique for the recovery of strongyloid larvae from small sample units of pasture. J Helminthol., v. 61, p. 1-10, 1967.

DURIE, P.H. Parasitic gastro-enteritis of cattle the distribution and survival of infective Strongyle larvae on pasture. Aust J Agric Res., v. 12, p. 1200-1211, 1961.

GOLDBERG, A. Development and survival on pasture of gastro-intestinal nematode parasites of cattle. J Parasitol., v. 54, p. 856-862, 1968.

GONÇALVES, P.C., VIEIRA, J.M.S. Primeira contribuição a sobrevivência de ovos e larvas de namatódeos de ovinos na pastagem, no Rio Grande do Sul. Rev Fac Agr Vet., Porto Alegre, v. 6, p. 95-103, 1963.

GORDON, H. M.C.L., WHITLOCK, H.V. A new technique for counting nematode eggs in shep faeces. J Coun Sci Ind Res Aust., v. 12, p. 50-52, 1939.

GORDON, H.M. The epidemiology of parasitic disease, with special reference to studies with nematode parasites of sheep. Aust Vet J., v. 24, p. 17-45, 1948.
GUIMARÃES, M.P. Variação estacional de larvas infestantes de nematóides parasitos de bovinos em pastagens de Cerrado de Sete Lagoas, M.G. Brasil. Arq Esc Vet., UFMG, v. 24, p. 97-113, 1972.

KEITH, R.K. The differentiation of the infective larvae of some common nematode parasites of cattle. Aust J Zool J., v. 1, p. 223-235, 1953.

LEVINE, N.D., TODD, K.S. Jr. Micrometeorological factors involved in development and survival of free-living stages of the sheep nematodes Haemonchus contortus and Trichostrongylus colubriformis. Review Intern J Biometeorol., v. 19, p. 174-183, 1975.

MELO, H.J.H. População de larvas infestantes de nematóides gastrintestinais de bovinos nas pastagens, durante a estação seca, em zona de cerrado do sul de Mato Grosso. Arq Esc Vet UFMG., v. 29, p. 89-95, 1977.

REINECKE, R.K. The role of infested dung in the transmission of nematode parasites of cattle. J S Afr Med. Ass., v. 31, p. 45-52, 1960 a.

A field sdudy of some nematode parasytes of bovines in a semi-arid and with special reference to their biology and possible methods of prophilaxis Onderstepoort J. Vet. Res., v. 28, p.364$464,1960 b$.

Helminth diseases in domestic animals in relation to their environment. S Afr J Sci., v. 66, p. 192-198, 1970.

ROBERT, F.H.S., O'SULLIVAN, P.I. Methods for egg counts and larval cultures for Strongyles infecting the gastro-intestinal tract of cattle. Aust J Agric Res., v.1, p. 99-192, 1950.

ROSE, J.H. Parasitic gastro-enteritis in cattle. Factors influencing the time of the increase in the worn population of pastures. Res Vet Sci., v. 2, p. 199-208, 1970.

ROSEMBERG, N.J. Microclimate: The biological Environment. New Yale. Johs Wile e Sons, 1974.

SEMEAL, M.G., ROBINSON, G.G., FRASER, G.C. Seasonal availabilith of nematode larvae on pastures grazed by cattle in new south wales. Aust Vet J., n. 56, p. 74-79, 1980.

SKINNER, W.D., TODD, R.S., Jr. Lateral Migration of Haemonchus contortus larvae on Pasture. A J Vet Res., v. 1, p. 395-398, 1980.

UENO, H. A simple method of detection of Dictyocaulus viviparus larvae in faeces of cattle I. procedure and basic tests. Jap Vet Med Ass., v. 21, p. 255-259, 1968. 